\title{
Non-vitamin K oral anticoagulants (NOACs) in patients with stroke and atrial fibrillation
}

\author{
Dejana R. Jovanović
}

\author{
University of Belgrade - Faculty of Medicine, Neurology Clinic, Clinical Centre of \\ Serbia, Dr Subotića 6, 11000 Belgrade, Serbia
}

Corresponding author: Dejana R. Jovanović, e-mail: dejana.r.jovanovic@gmail.com

\begin{abstract}
Summary
Patients with atrial fibrillation who had a previous transient ischemic attack or ischemic stroke had a significantly high risk of stroke recurrence and the introduction of oral anticoagulants should be mandatory. However, the long-term use of oral anticoagulants increases the risk of developing all types of intracranial hemorrhages. The advantages of non-vitamin $\mathrm{K}$ oral anticoagulants (NOACs) compared to warfarin are that they have a significantly lower risk for hemorrhagic stroke. They are preferred in elderly patients, those with small vessel disease, or those with previous intracerebral hemorrhage. The time of NOACs introduction after an ischemic stroke depends on its severity and the rule "1-3-6-12" days should be applied. The reintroduction of NOACs in patients with atrial fibrillation and previous intracerebral hemorrhage depends on its etiology and should be after about 4-8 weeks if the cardioembolic risk is high and the risk for intracranial hemorrhage small.
\end{abstract}

Keywords: ischemic stroke, intracranial hemorrhage, non-vitamin K oral anticoagulants, atrial fibrillation 


\section{Introduction}

Secondary prevention of an ischemic stroke (IS) depends on its cause. Aspirin is a drug of choice in the early phase of acute IS, which should be introduced within 48 hours of stroke onset. In the further course, antiplatelet or oral anticoagulant therapy is continued, depending on whether it is a cardioembolic or non-cardioembolic type of IS. Cardioembolic IS accounts for about $20-30 \%$ of all stroke patients (1). The most common cardiogenic cause of IS is atrial fibrillation (AF), which carries a high risk of developing the first IS, and even higher in patients who already had IS (2). The introduction of oral anticoagulants (OAC) in patients with $\mathrm{AF}$ reduces their risk of developing first IS by $67 \%$, and in secondary prevention by $66 \%(3,4)$. However, the fact is that some patients experience IS during an unregistered AF paroxysm which subsequent detection may be delayed, and thus the use of OAC is also delayed. Another important fact is that OACs carry a significant risk of hemorrhagic complications and that their long-term use is supported only when the cardioembolic cause of IS is confirmed. These facts raise two important questions. One is how to recognize cardioembolic IS, and the other is whether long-term anticoagulant therapy is safe.

\section{Cardioembolic stroke}

Cardioembolic IS is usually associated with a severe neurological deficit because the embolus is most often lodged in the proximal segments of the middle cerebral artery (ACM) or its branches (5). Cardioembolism is the cause of about $50 \%$ of all malignant ACM occlusions with a high mortality rate, in 34\% ACM branches occlusion and in $41 \%$ of all cortical infarcts $(5,6)$. Very rarely, cardioembolism is the cause of lacunar infarcts or transitory ischemic attacks (TIA) $(5,7)$. Interestingly, cardioembolic IS is not only localized in the anterior circulation, but also in the posterior circulation areas to a much greater extent than originally thought. The cerebellum, bilateral thalamus, and other multifocal infarcts in the posterior cranial fossa are the typical localization of infarcts in the posterior circulation (6). An important feature of cardioembolic infarcts is the presence of hemorrhagic transformation (HT) which is detected in as many as $71 \%$ of cases $(6,7)$. The typical clinical presentation of cardioembolic IS implies a large neurological deficit that develops rapidly with the punctum of clinical symptoms at the beginning of the disease, possible initial disturbance of consciousness, but also the possibility of rapid recovery of symptoms as a sign of spontaneous lysis of thrombus $(5,7,8)$. The neuroimaging often shows multiple infarcts of different ages in distinct vascular areas or cortical infarcts in the distal branches of large arteries, often with signs of HT (6).

The source of cardioembolism should be specified as follows: thrombus formation in the left ventricle (i.e. after large myocardial infarction, in the left ventricular aneurysm, cardiomyopathies), infective endocarditis, thrombosis of artificial valves, paradoxical embolism (patent foramen ovale, atrial septal defect), aortic plaque embolization, and 
most frequently left atrial appendage thrombosis in atrial fibrillation and/or rheumatic valvule disease. However, the most common cause of cardioembolic IS with about $50 \%$ prevalence is AF (9). It is a major risk factor for IS, as one out of five patients with AF develops IS and one out of four over the age of 80 (9). The early recurrences of IS in patients with AF are registered in about $12 \%$ of patients (7). The presence of AF at the onset of acute IS is associated with significantly higher mortality compared with patients without AF. Thus, the 30-day mortality of IS with AF is $32.5 \%$, and for those without AF $16.2 \%(10)$.

The permanent AF carries a high risk of developing IS, but it is confirmed that the risk is also significant in paroxysmal AF. The paroxysmal AF is found as a cause of IS in about $6.2 \%$, and in patients with cryptogenic stroke in $13.4 \%$ of cases (11). The detection of paroxysmal AF in patients with previous IS increases with the duration of monitoring. Thus, with continuous ECG monitoring within the first 24-72 hours after the onset of IS, paroxysmal AF can be detected in 2.4 to $8.3 \%$, with subsequent 24-hour Holter ECG in $3-5 \%$, and with repeated or prolonged Holter ECG in up to $14 \%$ of IS patients (11-13). In patients with cryptogenic IS, paroxysmal AF is detected by implantable ECG recorders over 36 months in about $30 \%$ (14).

\section{Anticoagulant therapy in the secondary prevention of IS in patients with AF}

The patients with IS and AF have a high risk of early recurrence of stroke, and therefore it would be prudent to introduce anticoagulants immediately after its onset. On the other hand, the frequent occurrence of HT in the presence of anticoagulant therapy increases the risk of developing symptomatic intracerebral hemorrhage (ICH), and it should be cautious with the introduction of OAC in the early phase of acute IS. Also, the long-term use of OAC in patients with the previous IS increases the risk of developing ICH, especially in those with small vessel disease (SVD). The CHADS 2 VASc and HASBLED scores are not of great importance in a risk assessment in patients with previous IS. In both scores, recent stroke increases the risk for either hemorrhagic stroke or recurrence of IS, and they do not consider other significant risk factors such as the presence of ischemic leukoencephalopathy or leukoaraiosis. The risk of developing symptomatic ICH is increased in the presence of major infarction, HT, uncontrolled hypertension, conditions with a hemorrhagic tendency (e.g. thrombocytopenia), previous hemorrhagic strokes, in combined antithrombotic therapy or non-steroidal anti-platelet therapy (15). The HASBLED score is always a great tool to evaluate a patient's risk for hemorrhagic complications, including intracranial hemorrhage. Therefore, in each patient with IS, his or her risk of recurrence of IS or developing hemorrhagic stroke should be balanced and then decide whether or not to use OAC.

For decades, vitamin $\mathrm{K}$ antagonists (VKA) have been unique and highly effective medications used in the primary and secondary prevention of IS in patients with AF, but 
with some limitations such as a narrow therapeutic window, the need for frequent laboratory monitoring, and numerous food and drug interactions. To overcome these limitations of VKA medications, new direct non-vitamin K oral anticoagulants (NOACs) have been developed in recent decades. The NOACs could be considered ideal because they do not interact with food, have few interactions with other drugs, and have a predictable therapeutic response (16). Dabigatran acts on thrombin and apixaban, rivaroxaban and edoxaban on factor Xa.

\section{Efficacy and safety of NOACs in the secondary prevention of IS in patients with $\mathbf{A F}$}

The efficacy and safety of NOACs in secondary prevention of IS have not been investigated in special randomized controlled trials (RCS), but significant information was provided by the subanalysis of patients with previous IS or TIA from RE-LY, ROCKET-AF and ARISTOTLE studies, which introduced these medications in practice (17-19). In all these studies, patients with a previous TIA or IS had a significantly higher risk of stroke recurren ce, regardless of whether they were on NOACs or warfarin.

In the RE-LY study, there were 3623 (20\%) patients with a previous IS or TIA (17). Dabigatran $110 \mathrm{mg}$ and $150 \mathrm{mg}$ were as effective as warfarin in reducing the risk of stroke recurrence or systemic embolism (Table I). A lower dose of dabigatran had a $30 \%$ significantly lower all-cause mortality compared to warfarin, an $80 \%$ lower relative risk of intracranial hemorrhage, and lower major bleeding by about 34\%. A higher dose of dabigatran reduced the relative risk for intracranial hemorrhage by $59 \%$ but carried an increased risk for gastrointestinal (GI) bleeding (Table II).

Table I The efficacy of NOACs versus VKA in secondary stroke prevention in patients with atrial fibrillation

Tabela I Efikasnost NOAK u poređenju sa VKA u sekundarnoj prevenciji moždanog udara kod bolesnika sa atrijalnom fibrilacijom

\begin{tabular}{|c|c|c|c|c|}
\hline & $\begin{array}{l}\text { RE- LY } 110 \\
\text { OR }(95 \% \mathrm{CI})\end{array}$ & $\begin{array}{l}\text { RE-LY 150 } \\
\text { OR }(95 \% \mathrm{CI})\end{array}$ & $\begin{array}{c}\text { ROCKET -AF } \\
\text { OR }(95 \% \mathrm{CI})\end{array}$ & $\begin{array}{c}\text { ARISTOTLE } \\
\text { OR }(95 \% \mathrm{CI})\end{array}$ \\
\hline Stroke or SE & $\begin{array}{c}0.84 \\
(0.58-1.21)\end{array}$ & $\begin{array}{c}0.75 \\
(0.52-1.09)\end{array}$ & $\begin{array}{c}0.94 \\
(0.77-1.17)\end{array}$ & $\begin{array}{c}0.76 \\
(0.56-1.03)\end{array}$ \\
\hline Stroke & $\begin{array}{c}0.89 \\
(0.61-1.31)\end{array}$ & $\begin{array}{c}0.76 \\
(0.52-1.13) \\
\end{array}$ & $\begin{array}{c}0.98 \\
(0.79-1.22)\end{array}$ & $\begin{array}{c}0.71 \\
(0.52-0.97)^{*}\end{array}$ \\
\hline $\begin{array}{l}\text { Ischemic or } \\
\text { unknown stroke }\end{array}$ & $\begin{array}{c}1.28 \\
(0.84-1.94)\end{array}$ & $\begin{array}{c}1.02 \\
(0.66-1.57)\end{array}$ & $\begin{array}{c}1.04 \\
(0.82-1.31)\end{array}$ & $\begin{array}{c}0.86 \\
(0.60-1.23)\end{array}$ \\
\hline $\begin{array}{l}\text { Fatal or invalidating } \\
\text { stroke }\end{array}$ & $\begin{array}{c}0.81 \\
(0.52-1.27)\end{array}$ & $\begin{array}{c}0.72 \\
(0.46-1.13)\end{array}$ & $\begin{array}{c}0.93 \\
(0.69-1.24)\end{array}$ & $\begin{array}{c}0.87 \\
(0.57-1.34)\end{array}$ \\
\hline
\end{tabular}

NOACs non-vitamin $\mathrm{K}$ oral anticoagulants, VKA vitamin K antagonists,

SE systemic embolism

* Statistically significant $(\mathrm{p}<0.05$ or $\mathrm{p}<0.01)$ 
In the ROCKET-AF study, as many as $52 \%$ of patients had previous TIA or IS with a large number of vascular risk factors (18). A subanalysis of these patients showed that rivaroxaban was as effective as warfarin in reducing the risk of stroke, systemic embolism, or death (Table I). Rivaroxaban in this group of patients with previous TIA/IS had the same safety profile as warfarin, with the same risk of intracranial hemorrhage, $\mathrm{ICH}$, or major bleeding, but with a significant reduction in the relative risk of fatal bleeding for about $46 \%$ compared to warfarin (Table II).

Table II Safety of NOACs versus VKA in secondary stroke prevention in patients with atrial fibrillation

Tabela II Bezbednost NOAK u poređenju sa VKA u sekundarnoj prevenciji moždanog udara kod bolesnika sa atrijalnom fibrilacijom

\begin{tabular}{|l|c|c|c|c|}
\hline & $\begin{array}{c}\text { RE- LY 110 } \\
\text { OR }(95 \% \mathrm{CI})\end{array}$ & $\begin{array}{c}\text { RE-LY 150 } \\
\text { OR }(95 \% \mathrm{CI})\end{array}$ & $\begin{array}{c}\text { ROCKET -AF } \\
\text { OR }(95 \% \mathrm{CI})\end{array}$ & $\begin{array}{c}\text { ARISTOTLE } \\
\text { OR }(95 \% \mathrm{CI})\end{array}$ \\
\hline All-cause mortality & $\mathbf{0 . 7 9}$ & 0.98 & 0.97 & 0.88 \\
& $\mathbf{( 0 . 5 2 - 0 . 9 5 ) *}$ & $(0.74-1.29)$ & $(0.82-1.14)$ & $(0.69-1.12)$ \\
\hline Intracranial & $\mathbf{0 . 2 6}$ & $\mathbf{0 . 4 3}$ & 0.73 & $\mathbf{0 . 4 0}$ \\
hemorrhage & $\mathbf{( 0 . 1 3 - 0 . 5 0 ) *}$ & $\mathbf{( 0 . 2 4 - 0 . 7 9 ) *}$ & $(0.47-1.13)$ & $\mathbf{( 0 . 2 4 - 0 . 6 8 ) *}$ \\
\hline Hemorrhagic stroke & $\mathbf{0 . 2 0}$ & $\mathbf{0 . 3 1}$ & 0.73 & $\mathbf{0 . 4 2}$ \\
& $\mathbf{( 0 . 0 8 - 0 . 4 8 ) *}$ & $\mathbf{( 0 . 1 4 - 0 . 7 0 ) *}$ & $(0.42-1.25)$ & $\mathbf{( 0 . 2 3 - 0 . 7 7 ) ^ { * }}$ \\
\hline Major hemorrhage & $\mathbf{0 . 6 5}$ & 1.02 & 0.96 & $\mathbf{0 . 7 4}$ \\
& $\mathbf{( 0 . 4 8 - 0 . 9 0 ) *}$ & $(0.76-1.36)$ & $(0.76-1.19)$ & $\mathbf{( 0 . 5 5 - 0 . 9 9}) *$ \\
\hline GI hemorrhage & 1.00 & $\mathbf{1 . 6 8}$ & NA & 0.84 \\
& $(0.61-1.63)$ & $\mathbf{( 1 . 1 1 - 2 . 5 7 ) *}$ & & $(0.45-1.57)$ \\
\hline
\end{tabular}

NOACs non-vitamin $\mathrm{K}$ oral anticoagulants, VKA vitamin $\mathrm{K}$ antagonists, GIT gastrointestinal, NA not available

* Statistically significant $(\mathrm{p}<0.05$ or $\mathrm{p}<0.01)$

In the ARISTOTLE study, there were 3436 (19\%) patients with previous TIA/IS and apixaban was shown to be more effective than warfarin in this patient population in reducing the risk of recurrence of any type of stroke by about $29 \%$ and even by about $60 \%$ risk reduction for hemorrhagic stroke (19) (Table I). Compared to warfarin, apixaban has a $27 \%$ lower risk of major bleeding and a $63 \%$ lower risk of intracranial hemorrhage (Table II).

A meta-analysis of 14527 patients with previous TIA/IS in these three RCT showed that the introduction of NOACs significantly reduced the incidence of stroke or systemic embolism by about $15 \%$ compared with warfarin (20). The use of NOACs was associated 
with a significantly lower risk of major bleeding (by $\sim 14 \%$ ), mainly due to a reduction in the risk of hemorrhagic stroke (by 56\%) (20).

Having in mind all the advantages of NOACs in relation to warfarin, above all their safety profile, and the fact that they reduce the risk of hemorrhagic stroke and intracranial hemorrhage to which are particularly predisposed patients with previous IS, the recommendation of the European Society of Cardiology (ESC) and the European Stroke Organization (ESO) is that the NOACs should have preference over warfarin or aspirin in patients with AF and previous IS $(21,22)$.

\section{The NOACs in specific groups of patients with previous IS and AF}

In RCT subanalyses that compared the efficacy and safety of NOACs against VKA, it was not shown that the use of NOACs has a different effect in the elderly population compared to younger people (17-19). The ESO Guideline gives preference to NOACs over VKA in the elderly population, although there is currently no data on whether there are differences between older and younger patients with previous IS and AF (22).

There are currently no data on the use of OAC in patients with previous cognitive deficits. The introduction of OAC in these patients should consider the degree of cognitive decline, ability to understand, quality of life and life expectancy, the possibility of poor therapeutic adherence, and higher risks of hemorrhagic complications. The ESO Guideline gives preference to NOACs over VKA in the secondary prevention of IS in patients with AF and cognitive deficits (22).

There are currently no studies comparing the use of NOACs with VKA in patients with previous IS who have mild or moderate renal insufficiency. In the secondary prevention of IS, the use of NOACs is recommended in these patients in adjusted doses as well as in primary prevention (22).

\section{The NOACs in patients with SVD}

The SVD is a spectrum of changes occurring in the small blood vessels of the brain and is manifested by the presence of small multiple lacunar infarcts, white matter hyperintensities (WMH), or cerebral microbleeds (CMB). They account for about $25 \%$ of the causes of IS and $80 \%$ of the causes of ICH $(23,24)$. The fact that SCD is associated with the occurrence of ICH often makes neurologists hesitant to introduce OACs in these patients or to refrain from their introduction. The WMH changes and CMB that carry an increased risk of developing $\mathrm{ICH}$, are present with significant frequency among patients with AF (25). A CROMIS-2 study of patients with previous IS and AF treated with VKA or NOACs showed that the presence of $\mathrm{CMB}$ increased the risk of developing symptomatic ICH by 3.7 times, compared with patients in whom CMB was not detected (26). Given these facts, having detected the SVD neuroimaging markers could be useful to clinicians in predicting the risk of introducing long-term OAC in patients with previous 
IS and AF. However, it is necessary to wait for ongoing studies to provide solid recommendations on this issue. Theoretically, NOACs may have an advantage over VKA in patients with SVD and previous AF (22).

\section{The NOACs in an embolic stroke of unknown source (ESUS)}

Secondary prevention of stroke depends on timely and adequate detection of the stroke mechanism. Namely, in cardioembolic stroke, the therapy of choice in secondary stroke prevention is anticoagulant therapy, because aspirin is not effective enough. About $25 \%$ of all IS are cryptogenic and antiplatelet therapy is recommended for secondary prevention. However, the fact is that based on clinical and neuroimaging criteria, the cardioembolic mechanism of cryptogenic stroke can be assumed, as well as that it can be paroxysmal AF. For these reasons, the Embolic Stroke of Undetermined Source (ESUS) has emerged as a separate entity among cryptogenic strokes in recent years (27). According to available data, as much as $14-30 \%$ of ESUS may be due to paroxysmal AF (11-14). The criteria for the diagnosis of ESUS are the presence of non-lacunar IS on head $\mathrm{CT} / \mathrm{MRI}$, the absence of extra/intracranial atherosclerosis narrowing the lumen $>50 \%$ in the irrigation area of ischemia, the absence of high-risk cardioembolic cause or other specific causes of IS (arteritis, dissection, vasospasm, etc.) (27). In order to confirm the ESUS, it is necessary to conduct a detailed etiological diagnosis of IS (head CT/MRI, ECG, transthoracic echocardiography, ECG monitoring $>24 \mathrm{~h}$ with automatic rhythm detection, neurovascular imaging of extra and intracranial blood vessels).

The introduction of the ESUS concept intended to examine whether the introduction of NOACs in this particular group of patients is more effective in secondary prevention than antiplatelet therapy, which is currently the only recommended antithrombotic therapy in cryptogenic IS. The preterm completed NAVIGATE ESUS study did not show a higher efficacy of rivaroxaban compared to aspirin in patients with ESUS, while the risk of major bleeding in the rivaroxaban group was significantly higher, especially for intracranial hemorrhages (28). Neither dabigatran compared to aspirin did not show its advantage in patients with ESUS, but there was no difference in the risk of major bleeding between the two groups of patients (29). Given the results of these two studies, aspirin remains the only recommended therapy in patients with ESUS. It is possible that in selected groups of patients with ESUS, the NOACs may be effective. Thus, the subanalysis of NAVIGATE ESUS showed that rivaroxaban was significantly more effective in patients with ESUS and PFO compared with aspirin (30). The ongoing studies compare the efficacy of apixaban with aspirin in patients with cryptogenic IS and atrial cardiopathy (ARCADIA) or their effectiveness in preventing the occurrence of new ischemic lesions on MRI over a period of 12 months (ATTICUS) $(31,32)$. 


\section{When is the right time to introduce NOACs after acute IS?}

The answer to this question is not easy to give, because in all RCT (RE-LY, ROCKET-AF, ARISTOTLE) the exclusion criterion for entering the study was TIA or IS in the previous 7-14 days, and in some of them the exclusion criterion was a severe stroke in the previous 3-6 months (17-19). Data from observational studies, as well as of control groups in RCT, indicate a high risk for early recurrence of stroke among patients with AF within the first 14 days, which is around $0.5-1.3 \%$ per day $(22,33)$. On the other hand, in this early period, after large IS such as those in patients with AF, there is a high risk of HT which would be further increased with the introduction of therapeutic doses of anticoagulants (34).

The HAEST study did not show the superiority of dalteparin in the first 14 days from the onset of IS compared with aspirin in terms of preventing recurrence of IS, but there were no major hemorrhagic complications (35). A meta-analysis of subgroups of patients with AF in whom heparin was administered within the first 48 hours after the onset of IS did not show a significant reduction in the risk of stroke recurrence but did confirm the existence of a significantly increased risk of intracranial hemorrhage (36). However, one recent meta-analysis of 7 prospective cohort studies with 4912 patients with acute IS and AF showed that early introduction of NOACs (median 5 days) carries a significantly lower risk for ICH compared to VKA and this effect is present both in those with small (NIHSS $\leq 3$ ) or severe neurological deficit (NIHSS $>15$ ), older than 80 years or those treated with recanalization therapy (37).

There are expert opinions that in patients with TIA or minor stroke $(<1.5 \mathrm{~cm})$ the introduction of NOACs should be similar to those of warfarin, and that they can be safely introduced after about 24 to 48 hours from the onset of TIA/IS (22). Their position is supported by the results of two small studies with early introduction of rivaroxaban and dabigatran in patients with minor stroke $(38,39)$. In the study of Hong et al. no significant difference in the incidence of stroke recurrence or symptomatic hemorrhage was found between rivaroxaban and warfarin when administered within 5 days of the onset of minor IS (median NIHSS 2) (38). In the DATAS II study, there was no significant difference in the incidence of symptomatic parenchymal ICH when administering aspirin or dabigatran within the first 72 hours in patients with the previous minor IS (NIHSS <9) (39). In patients with minor IS, prior administration of aspirin was not required given the results of an AVERROES study showing that apixaban was more effective than aspirin (40). Also, there is no need for overlap with low molecular weight heparins (LWH), because their use in the early phase of IS in patients with AF carries an increased risk of HT and they have a worse outcome compared to those in which only OAC is given (41).

In patients with moderate to severe $I S$ and $\mathrm{AF}$, the risk of developing $\mathrm{ICH}$ outweighs the benefit of anticoagulants in the first days after stroke onset. Most experts and guidelines state that NOACs should be started within 4 - 14 days from the onset of 
IS, considering the degree of neurological deficit and the size of the infarction $(21,22,41,42)$. In the absence of data from the RCT, a consensus was reached on the introduction of NOACs after IS in AF patients illustrated by the "1-3-6-12 day" rule (43) (Table III). In severe and disabling forms of IS, the use of NOACs can be delayed even after 2 weeks, with low dose aspirin given until their introduction $(21,22,33)$. In deciding when to introduce NOACs, it may help to repeat head CT after about 5 - 7 days. If there is no HT, aspirin can be stopped and NOAC may be introduced, and in case of its presence, the use of NOACs is postponed and other risk factors for HT are considered.

Table III Time of NOACs introducing after acute ischemic stroke

Tabela III Vreme uvođenja NOAK posle akutnog ishemijskog moždanog udara

\begin{tabular}{|l|c|}
\hline \multicolumn{1}{|c|}{ Severity of IS } & $\begin{array}{c}\text { Time of NOACs introduction } \\
\text { TIA }\end{array}$ \\
\hline Minor IS (NIHSS $<$ 8) & $\begin{array}{c}\text { immediately after neuroimaging } \\
\text { excludes ICH }\end{array}$ \\
\hline Moderate IS (NIHSS $8-16)$ & $3-5$ days after stroke onset \\
\hline Severe IS (NIHSS $>16)$ & 5-7 days after stroke onset \\
\hline
\end{tabular}

NOACs non-vitamin K oral anticoagulants, TIA transient ischemic attack, IS ischemic stroke, ICH intracerebral hemorrhage

\section{The of intravenous thrombolysis in the treatment of IS in patients on NOACs}

The patients with acute IS are candidates for intravenous thrombolysis (IVT) in the first 4.5 hours of stroke onset. In patients on previous VKA therapy, IVT is recommended if the INR is less than 1.7 (42). However, in patients on NOACs there is no reliable quantitative coagulation test that would allow IVT to be used when its values are below a safe limit. In patients on dabigatran, prolonged aPTT of any value precludes the use of IVT. The specific tests of the anticoagulant effect of some NOACs take a long time for performing them, they are not routinely available, and some are qualitative tests. Only the complete absence of the anticoagulant effect of NOAC in these tests can enable the use of IVT.

Since the half-life of NOACs is between 8 and 17 hours, IVT administration could be safe after 24 hours and quite safe after 48 hours from the last dose of NOAC (2-4 times the half-life) (43-45). For patients with renal insufficiency, this period should be longer, up to 96 hours. In patients who have previously been on dabigatran, it is possible to use idarucizumab before IVT, if mechanical thrombectomy is not possible (45). 


\section{The NOACs and intracranial hemorrhage}

The long-term use of OAC increases the risk of developing all types of intracranial hemorrhage (46). The greatest risk of developing intracranial hemorrhage is with older age, earlier IS, and concomitant use of antiplatelet therapy. Most of them are ICH and subdural hematomas, and less often they are subarachnoid hemorrhages or post-traumatic epidural hematomas (47). The use of NOACs in comparison with warfarin reduces the risk of intracranial hemorrhage by $33-70 \%$ depending on the medication and its dose (17-19). The NOACs-ICH compared to those induced by VKA have a smaller volume, a smaller initial neurological deficit with a lower incidence of severe $\mathrm{ICH}$, have lower mortality, and a better functional outcome (48).

The initial approach in patients who developed intracranial hemorrhage during the use of NOACs implies an assessment of the effect of the drug, i.e. laboratory evaluation of their effect. Normal values of aPTT (dabigatran) or anti-Xa activity (apixaban, rivaroxaban) should question whether NOACs are the cause of intracranial hemorrhage. The efficacy and safety of the recommended measures in the event of major bleeding associated with NOACs are questionable when it comes to intracranial hemorrhage. The use of activated or inactivated prothrombin complex concentrate or with the significantly delayed effect fresh frozen plasma is recommended $(21,49)$. If available, the use of idarucizumab as a specific reversing agent in dabigatran is recommended and haemodialysis may be useful (21).

\section{Introduction of NOACs after intracranial hemorrhage}

The reintroduction of OAC in a patient with AF and previous $\mathrm{ICH}$ depends on its etiology. Thus, if the intracranial hemorrhage was the result of a condition that can be controlled and treated (e.g. hypertensive hemorrhage), the reintroduction of OAC should be considered. On the other hand, in conditions with a continuously increased risk of bleeding (e.g. amyloid angiopathy), the indications for the reintroduction of OAC should be carefully weighed.

A retrospective analysis of patients with $\mathrm{OAC}$ - ICH showed that the reintroduction of OAC significantly reduced the risk of ischemic events by 3 times and did not increase the risk of hemorrhagic complications (50). The same analysis showed that patients in whom OAC were reintroduced have significantly greater long-term survival. These results were confirmed by a meta-analysis involving 7 studies with 2452 AF patients who had previously experienced intracranial hemorrhage associated with OAC (51). This analysis showed that $\mathrm{OAC}$ reintroduction carried a significantly lower risk of developing IS over 6 weeks to a year, without increasing the risk for $\mathrm{ICH}$, compared to patients without antithrombotic therapy or those on antiplatelets (51). Another meta-analysis of approximately 1012 patients with ICH showed that the reintroduction of OAC significantly reduced the risk of death and the occurrence of IS regardless of whether it 
was a lobar or non-lobar hematoma and that there was no significant increase in the risk of ICH recurrence in either of the two types of a hematoma (52).

The ESO guideline states that the reintroduction of OAC after ICH should be considered with a prior careful risk-benefit assessment (22.) The ESC guideline recommends reintroduction of OAC in patients with $\mathrm{AF}$ and previous $\mathrm{OAC}-\mathrm{ICH}$ after about 4-8 weeks if the cardioembolic risk is high and the risk for intracranial hemorrhage small (21). The refrain of the OAC reintroduction in patients with previous intracranial hemorrhage and AF should stand when bleeding has occurred at adequate doses of OAC, in the elderly, in the presence of uncontrolled hypertension, lobar hematomas, an increasing number of $\mathrm{CMB}$ on MRI, chronic alcohol consumption, or the need for concomitant antiplatelet therapy (21). Although there are currently no studies comparing the reintroduction of VKA or NOAC after previous intracranial hemorrhage, the opinion of experts is that the less risky NOACs should be the choice in such cases (22).

\section{References}

1. Kolominsky-Rabas PL, Weber M, Gefeller O, Neundoerfer B, Heuschmann PU. Epidemiology of ischemic stroke subtypes according to TOAST criteria: incidence, recurrence, and long-term survival in ischemic stroke subtypes: a population-based study. Stroke. 2001;322(12):2735-2740.

2. Stroke Risk in Atrial Fibrillation Working Group. Independent predictors of stroke in patients with atrial fibrillation: a systematic review. Neurology. 2007;69:546-554.

3. Stroke Prevention in Atrial Fibrillation Investigators. Stroke Prevention in Atrial Fibrillation. Final results. Circulation. 1991;84:527-39.

4. European Atrial Fibrillation Trial Study Group. Secondary prevention in non-rheumatic atrial fibrillation after transient ischaemic attack or minor stroke. Lancet. 1993;342:1255-1262.

5. Sachdeva G, Saeed A, Jani V, Razak A. Radiological portrait of embolic strokes. Cardiol Clin. 2016;34(02):269-278.

6. O'Carroll CB, Barrett KM. Cardioembolic Stroke. Continuum (Minneap Minn). 2017;23(1):111132.

7. Arboix A, Alió J. Acute cardioembolic stroke: an update. Expert Rev Cardiovasc Ther. 2011;9:3679.

8. Sacchetti DC, Furie KL, Yaghi S. Cardioembolic Stroke: Mechanisms and Therapeutics. Semin Neurol. 2017;37:326-338.

9. Kamel H, Healey JS. Cardioembolic stroke. Circ Res. 2017;120:514-526. 
10. Marini C, De Santis F, Sacco S, Russo T, Olivieri L, Totaro R, Carolei A. Contribution of atrial fibrillation to incidence and outcome of ischemic stroke: results from a population-based study. Stroke. 2005;36(6):1115-9.

11. Kishore A, Vail A, Majid A, Dawson J, Lees KR, Tyrrell PJ, Smith CJ. Detection of atrial fibrillation after ischemic stroke or transient ischemic attack: a systematic review and meta-analysis. Stroke. 2014;45(2):520-6.

12. Continuous Rizos T1, Güntner J, Jenetzky E, Marquardt L, Reichardt C, Becker R, Reinhardt R, Hepp T, Kirchhof P, Aleynichenko E, Ringleb P, Hacke W, Veltkamp R. Stroke unit electrocardiographic monitoring versus 24-hour Holter electrocardiography for detection of paroxysmal atrial fibrillation after stroke. Stroke. 2012;43(10):2689-94.

13. Wachter R, Gröschel K, Gelbrich G, Hamann GF, Kermer P, Liman J, et al; Find-AF(randomised) Investigators and Coordinators. Holter-electrocardiogram-monitoring in patients with acute ischaemic stroke (Find-AFRANDOMISED): an open-label randomised controlled trial. Lancet Neurol. 2017;16(4):282-290.

14. Sanna T, Diener HC, Passman RS, Di Lazzaro V, Bernstein RA, Morillo CA, Rymer MM, Thijs V, Rogers T, Beckers F, Lindborg K, Brachmann J; CRYSTAL AF Investigators. Cryptogenic stroke and underlying atrial fibrillation. N Engl J Med. 2014;370(26):2478-86.

15. Álvarez-Sabín J, Maisterra O, Santamarina E, Kase CS. Factors influencing haemorrhagic transformation in ischaemic stroke. Lancet Neurol. 2013;12(7):689-705.

16. Schulman S. Advantages and limitations of the new anticoagulants. J Int Med. 2014;275:1-11.

17. Connolly SJ, Ezekowitz MD, Yusuf S, et al. Dabigatran versus warfarin in patients with atrial fibrillation. N Engl J Med. 2009;361:1139-51.

18. Patel MR, Mahaffey KW, Garg J, et al. Rivaroxaban versus warfarin in nonvalvular atrial fibrillation. N Engl J Med. 2011;365(10):883-91.

19. Granger CB, Alexander JH, McMurray JJ et al. Apixaban versus warfarin in patients with atrial fibrillation. N Engl J Med. 2011;365(11):981-92.

20. Ntaios G, Papavasileiou V, Diener HC, Makaritsis K, Michel P. Nonvitamin-K-antagonist oral anticoagulants in patients with atrial fibrillation and previous stroke or transient ischemic attack: a systematic review and meta-analysis of randomized controlled trials. Stroke. 2012;43:3298-3304.

21. 2016 ESC Guidelines for the management of atrial fibrillation developed in collaboration with EACTS. Eur Heart J. 2016;37:2893-2962.

22. Klijn CJM, Paciaroni M, Berge E, Korompoki E, Korv J, Lal A, Putaala J, Werring D. Antithrombotic treatment for secondary prevention of stroke and other thromboembolic events in patients with stroke or transient ischemic attack and non-valvular atrial fibrillation: A European Stroke Organisation guideline. Eur Stroke J. 2019;4(3):198-223.

23. Pantoni L. Cerebral small vessel disease: from pathogenesis and clinical characteristics to therapeutic challenges. Lancet Neurol. 2010;9:689-701.

24. Wilson D, Adams ME, Robertson F, et al. Investigating intracerebral haemorrhage. BMJ. 2015; 350:h2484. 
25. Haeusler KG, Wilson D, Fiebach JB, et al. Brain MRI to personalise atrial fibrillation therapy: current evidence and perspectives. Heart. 2014;100:1408-1413.

26. Wilson D, Ambler G, Shakeshaft C, et al. Cerebral microbleeds and intracranial haemorrhage risk in patients anticoagulated for atrial fibrillation after acute ischaemic stroke or transient ischaemic attack(CROMIS-2): a multicentre observational cohort study. Lancet Neurol. 2018;17:539-547.

27. Hart RG, Diener H-C, Coutts SB, et al. Embolic strokes of undetermined source: the case for a new clinical construct. Lancet Neurol. 2014;13:429-38.

28. Hart RG, Sharma M, Mundl H, Kasner SE, et al. Rivaroxaban for stroke prevention after embolic stroke of undetermined source. N Engl J Med. 2018;378:2191-2201.

29. Diener HC, Sacco RL, Easton JD, Granger CB, Bernstein RA, Uchiyama S, et al; RE-SPECT ESUS Steering Committee and Investigators. Dabigatran for prevention of stroke after embolic stroke of undetermined source. N Engl J Med. 2019;380:1906-1917.

30. Kasner SE, Swaminathan B, Lavados P, Sharma M, Muir K, Veltkamp R, et al. Rivaroxaban or aspirin for patent foramen ovale and embolic stroke of undetermined source: a prespecified subgroup analysis from the NAVIGATE ESUS trial. Lancet Neurol. 2018;17:1053-1060.

31. Kamel H, Longstreth WT Jr, Tirschwell DL, Kronmal RA, Broderick JP, et al. The AtRial Cardiopathy and Antithrombotic Drugs In prevention After cryptogenic stroke randomized trial: Rationale and methods. Int J Stroke. 2019;14:207-214.

32. Geisler T, Poli S, Meisner C, Schreieck J, Zuern CS, Nägele T, et al. Apixaban for treatment of embolic stroke of undetermined source (ATTICUS randomized trial): Rationale and study design. Int J Stroke. 2017;12:985-990.

33. Seiffge DJ, Werring DJ, Paciaroni M, Dawson J, Warach S, Milling TJ, Engelter ST, Fischer U, Norrving B. Timing of anticoagulation after recent ischaemic stroke in patients with atrial fibrillation. Lancet Neurol. 2019;18:117-126.

34. Paciaroni M, Agnelli G, Corea F, et al. Early hemorrhagic transformation of brain infarction: rate, predictive factors, and influence on clinical outcome: results of a prospective multicenter study. Stroke. 2008;39:2249-56.

35. Berge E, Abdelnoor M, Nakstad PH, Sandset PM. Low molecular-weight heparin versus aspirin in patients with acute ischaemic stroke and atrial fibrillation: a double-blind randomised study. HAEST Study Group. Heparin in Acute Embolic Stroke Trial. Lancet. 2000; 355:1205-10.

36. Paciaroni M, Agnelli G, Micheli S, Caso V. Efficacy and safety of anticoagulant treatment in acute cardioembolic stroke: a meta-analysis of randomized controlled trials. Stroke. 2007;38:423-30.

37. Seiffge DJ, Paciaroni M, Wilson D, Koga M, Macha K, Cappellari et al. on behalf of the CROMIS2, RAF, RAF-OAC, SAMURAI, NOACISP LONGTERM, Erlangen and Verona registry collaborators. Direct oral anticoagulants versus vitamin K antagonists after recent ischemic stroke in patients with atrial fibrillation. Ann Neurol. 2019;85:823-834.

38. Hong KS, Kwon SU, Lee SH, et al. Rivaroxaban vs warfarin sodium in the ultra-early period after atrial fibrillation-related mild ischemic stroke: a randomized clinical trial. JAMA Neurol. 2017;74:1206-15. 
39. $\mathrm{Ng} \mathrm{KH}$, Sharma M, Benavente O, et al. Dabigatran following acute transient ischemic attack and minor stroke II (DATAS II). Int J Stroke. 2017;12:910-14.

40. Connolly SJ, Eikelboom J, Joyner C, Diener HC, Hart R, Golitsyn S, et al. Apixaban in patients with atrial fibrillation. N Engl J Med. 2011;364:806-17.

41. Paciaroni M, Agnelli G, Falocci N, Caso V, Becattini C, Marcheselli S, et al. Early Recurrence and Cerebral Bleeding in Patients With Acute Ischemic Stroke and Atrial Fibrillation: Effect of Anticoagulation and Its Timing: The RAF Study. Stroke. 2015;46:2175-82.

42. Powers WJ, Rabinstein AA, Ackerson T, et al. 2018 Guidelines for the early management of patients with acute ischemic stroke: a guideline for healthcare professionals from the American Heart Association/American Stroke Association. Stroke. 2018;49:e46-110.

43. Diener HC, Aisenberg J, Ansell J, Atar D, Breithardt B, Eikelboom J, et al. Choosing a particular oral anticoagulant and dose for stroke prevention in individual patients with non-valvular atrial fibrillation: part 2. Eur Heart J. 2017;38:860-868.

44. AHA/ASA Statement. Scientific rationale for the inclusion and exclusion criteria for intravenous alteplase in acute ischemic stroke. Stroke. 2016;47:581-641.

45. Diener HC, Bernstein R, Butcher K, Campbell B, Cloud G, Davalos A, et al. Thrombolysis and thrombectomy in patients treated with dabigatran with acute ischemic stroke: Expert opinion. Int $\mathrm{J}$ Stroke. 2017;12:9-12.

46. Witt DM, Delate T, Hylek EM, Clark NP, Crowther MA, Dentali F, et al. Effect of warfarin on intracranial hemorrhage incidence and fatal outcomes. Thromb Res. 2013;132:770-775.

47. Dowlatshahi D, Butcher KS, Asdaghi N, Nahirniak S, Bernbaum ML, Giulivi A, Wasserman JK, Poon MC, Coutts SB; Canadian PCC Registry (CanPro) Investigators. Poor prognosis in warfarinassociated intracranial hemorrhage despite anticoagulation reversal. Stroke. 2012;43:1812-7.

48. Tsivgoulis G, Lioutas VA, Varelas P, Katsanos AH, Goyal N, Mikulik R, et al. Direct oral anticoagulant- vs vitamin $\mathrm{K}$ antagonist-related nontraumatic intracerebral hemorrhage. Neurology. 2017;89:1142-1151.

49. Maajed A, Schulman S. Bleeding and antidotes in new oral anticoagulants. Best Pract Res Clin Haematol. 2013;26:191-202.

50. Kuramatsu JB, Gerner ST, Schellinger PD, et al. Anticoagulant reversal, blood pressure levels, and anticoagulant resumption in patients with anticoagulation-related intracerebral hemorrhage. JAMA. 2015;313:824-836.

51. Korompoki E, Filippidis FT, Nielsen PB, Del Giudice A, Lip GYH, Kuramatsu JB, et al. Long-term antithrombotic treatment in intracranial hemorrhage survivors with atrial fibrillation. Neurology. 2017;89:687-696.

52. Biffi A, Kuramatsu JB, Leasure A, et al. Oral anticoagulation and functional outcome after intracerebral hemorrhage. Ann Neurol. 2017;82:755-765. 


\title{
Ne-vitamin K oralni antikoagulansi (NOAK) kod bolesnika sa moždanim udarom i atrijalnom fibrilacijom
}

\author{
Dejana R. Jovanović \\ Univerziteta u Beogradu - Medicinski fakultet, Klinika za neurologiju KCS, \\ Dr Subotića 6, 11000 Beograd, Srbija
}

Autor za korespondenciju: Dejana R. Jovanović, e-mail: dejana.r.jovanovic@gmail.com

\section{Kratak sadržaj}

Bolesnici sa atrijalnom fibrilacijom koji su preležali tranzitorni ishemijski atak ili ishemijski moždani udar imaju značajno povećan rizik za recidiv moždanog udara, zbog čega je neophodno uvesti oralne antikoagulanse. Ipak, dugotrajna primena oralnih antikoagulanasa povećava rizik od nastanka svih vrsta intrakranijalnih hemoragija. Prednost ne-vitamin K oralnih antikoagulanasa (NOAK) u odnosu na varfarin je da nose značajno manji rizik za hemoragijski moždani udar. Oni imaju prednost kod starijih osoba, kod bolesnika sa bolešću malih krvnih sudova mozga i kod pacijenata sa ranijom intracerebralnom hemoragijom. Vreme uvođenja NOAK posle ishemijskog moždanog udara zavisi od njegove težine i veličine i predloženo je da se upotrebljava pravilo "1-3-6-12" dana. Ponovno uvođenje NOAK kod bolesnika sa atrijalnom fibrilacijom i prethodnom intracerebralnom hemoragijom zavisi od njenog uzroka i treba ih uvesti posle 4-8 nedelja ukoliko je kardioembolijski rizik velik, a rizik za intracerebralnu hemoragiju mali.

Ključne reči: ishemijski moždani udar, intrakranijalna hemoragija, ne-vitamin K oralni antikoagulansi, atrijalna fibrilacija 